\title{
Morphological and physiological variation among seagrass (Zostera marina) genotypes
}

\author{
A. Randall Hughes $\cdot$ John J. Stachowicz $\cdot$ \\ Susan L. Williams
}

Received: 29 June 2008 / Accepted: 1 December 2008 / Published online: 9 January 2009

(C) The Author(s) 2008. This article is published with open access at Springerlink.com

\begin{abstract}
Intraspecific variation in habitat-forming species can have important ecological consequences at the population, community, and ecosystem level. However, the contribution of genetic variation among individuals to these effects is seldom documented. We quantified morphological and physiological variation among genotypes of a marine foundation species, the seagrass Zostera marina. We grew replicate shoots of eight genetically distinct Zostera individuals collected from Bodega Bay, California, in a common garden environment and then quantified shoot production and morphology, nutrient uptake, and key photosynthetic parameters. We found that genotypes differed in shoot production, biomass, and both root and shoot nutrient uptake rates, even when corrected for genotype-specific biomass differences. In addition, the rank order of uptake ability differed for ammonium and nitrate, indicating that genotypes may exhibit resource partitioning of different forms of nutrients. Our results suggest that both niche complementarity among genotypes and the sampling/selection effect could contribute to previously observed positive effects of seagrass clonal diversity on resource utilization
\end{abstract}

Communicated by Martin Attril.

A. R. Hughes $\cdot$ S. L. Williams

Bodega Marine Laboratory, University of California,

Davis, PO Box 247, Bodega Bay, CA 94923, USA

Present Address:

A. R. Hughes $(\square)$

Coastal and Marine Laboratory, Florida State University,

3618 Highway 98, St. Teresa, FL 32358, USA

e-mail: rhughes@bio.fsu.edu

J. J. Stachowicz · S. L. Williams

Evolution and Ecology, University of California,

Davis, One Shields Avenue, Davis, CA 95616, USA and biomass production. Further, they highlight that genotypic variation in key traits of habitat-forming species could have measurable effects on community structure and function.

Keywords Biodiversity Coexistence . Community genetics · Genetic diversity . Niche complementarity

\section{Introduction}

Intraspecific variation in factors such as morphology, behavior, and resource use can have important population, community, and ecosystem-level effects. For instance, plants commonly exhibit inter-individual variation in secondary chemistry or palatability, with strong effects on plant community dynamics, herbivore fitness, and nutrient mineralization (Lankau and Strauss 2007; Schweitzer et al. 2004; Taylor et al. 2003). Despite the growing recognition of the importance of such variation to ecological processes (Bolnick et al. 2003; Clark et al. 2004), and a long history in evolutionary biology of partitioning phenotypic variation into component parts (Wright 1920), ecologists have relatively little understanding of the exact source of observed phenotypic variation within species. In particular, the contribution of differences among genotypes to variation in ecologically relevant population traits is seldom understood aside from a few well-studied systems (e.g., Populus hybrid complexes; Schweitzer et al. 2004; Whitham et al. 2006).

Variation among genotypes may be particularly important in foundation species (sensu Dayton 1972), which by their presence alter abiotic conditions and/or create habitat for other species. Because these species perform many of the same ecosystem processes associated with multiple species in other systems, variation among genotypes may 
increase community stability or reliability over time (Norberg et al. 2001; Tilman et al. 1997a). In fact, functional differentiation among genotypes is a prerequisite for ecological effects of genetic diversity (Hughes et al. 2008). Selection effects and niche partitioning are two mechanisms that account for non-additive diversity effects, and both rely on functional differences among genotypes (or species) in productivity or resource use, respectively (Cardinale et al. 2007; Hughes et al. 2008; Huston 1997; Tilman 1999). Despite growing evidence for the ecological importance of genetic diversity (Hughes et al. 2008), there is far less information regarding the nature of the functional variation among individuals that causes these effects.

We quantified the degree of morphological and physiological variation among genotypes of the seagrass Zostera marina. Zostera is a key marine foundation species, contributing to enhanced primary production, secondary production, and nutrient cycling in soft-sediment systems throughout the Northern Hemisphere (Moore and Short 2006). Despite documented variation in morphology, photosynthetic parameters, and nutrient uptake within and across seagrass beds (Dennison and Alberte 1982; Romero et al. 2006), the role of differences among genotypes in this variability is not known. Because Zostera plays such a major role in the structuring of the ecosystem, understanding the degree of genotypic variation is important to more than just the population biology of the species. Several previous studies have shown that increased genetic or genotypic diversity at the plot scale can lead to higher shoot densities, lower nutrient levels, and increased abundance or diversity of epifaunal invertebrates (Hughes and Stachowicz 2004; Reusch et al. 2005; Williams 2001). In addition, Zostera's ability to reproduce clonally allows single genotypes to dominate some areas (Reusch et al. 1999a); thus any variation among genotypes in their effect on the ecosystem and associated processes such as primary or secondary production could be maintained for long periods of time and influence large areas in space. Finally, Zostera is the target of extensive restoration in some areas (Orth et al. 2006), and ecological variation among genotypes could play a previously unrecognized role in the success of these efforts.

\section{Materials and methods}

\section{Experimental design}

We conducted a common garden experiment to quantify variation within and between Zostera genotypes in morphology, shoot and biomass production, photosynthetic rate, and nutrient uptake rate. Genotypes were identified using five DNA microsatellite loci designed specifically for this species (Reusch et al. 1999b; Reusch et al. 2000). Because of the difficulty of finding adequate numbers of shoots of the same genotype in the field, we propagated eight known genotypes in adjacent 300-1 outdoor flowthrough mesocosms at Bodega Marine Laboratory (BML) under ambient light and temperature conditions. Before planting the seagrass, we added 81 of sieved field-collected sediment to each mesocosm. Each mesocosm was then initiated with a single terminal shoot collected from one of eight different locations at $0.5 \mathrm{~m}$ mean lower low water tidal height in Bodega Harbor, California, in July 2004. The genetic distinctiveness of each of the original shoots was verified. Periodically during the propagation period we added equivalent numbers of Phyllaplysia taylori to each tank; these opisthobranch molluscs graze on epiphytic algae growing on Zostera but do not consume the seagrass itself (A. R. Hughes, unpublished data). No other organisms were intentionally added to the mesocosms, although some species (e.g., limpets, abalone, anemones) did colonize the tanks via the flow-through seawater system. Flow was maintained at a rate of approximately $60-70 \mathrm{ml} \mathrm{s}^{-1}$. Mesocosms were monitored weekly for the presence of flowering shoots or seagrass grazers; any present were removed.

In June 2006 we harvested ten terminal shoots (hereafter, 'clones') from each genotype for use in this experiment (see Thayer et al. 1984; Dennison et al. 1987 for diagrams of Zostera morphology). Seagrass photosynthetic capacity, pigment ratios, growth rates, and morphology acclimate rapidly to new environmental conditions when transplanted into different habitats, common gardens, and cultures (e.g., Dennison and Alberte 1985; Dennison and Alberte 1986; McMillan 1978). The 2-year acclimation period in mesocosms thus should have minimized environmental carryout from the habitat. To further minimize potential variation due to growing conditions, we propagated the ten terminal shoots of each genotype in individual pots in a common garden environment in the lab for 10 weeks. We did the same with 20 field-collected terminal shoots later confirmed to be from genetically distinct individuals. At least one new shoot per 'parent' was produced during this period. Shoot and rhizome lengths were standardized to 30 and $2.5 \mathrm{~cm}$, respectively, to minimize initial size differences. The clones were planted in sieved sediment in individual $15-\mathrm{cm}$-diameter pots and randomly assigned to locations in a single flow-through raceway at BML. The raceway was located outdoors under natural light conditions. Clones were randomly reassigned to different positions in the raceway every 2 weeks to minimize position effects.

After 10 weeks in the common garden, we assessed the performance of each clone with respect to the following metrics: (1) morphology and production (rhizome length, 
maximum root length, number of vegetative and reproductive shoots produced, shoot biomass, root biomass, and rhizome biomass); (2) nutrient uptake (shoot nitrate uptake, root/rhizome ammonium uptake); and (3) photosynthetic rate. Shoots that died $(n=3)$ or produced only flowering shoots $(n=7)$ were excluded from the analyses. To analyze variation among genotypes, we first conducted separate multivariate ANOVA (MANOVA) on the morphology/production and nutrient uptake data, with Zostera genotype as a random factor and a blocking factor for date when the clones were processed. When the MANOVA indicated significant differences among genotypes, we then conducted ANOVA for each response variable. There were no significant block $\times$ genotype interactions, so we omitted this term from our model. When there was a significant effect of genotype, we calculated broad sense heritability $\left(\mathrm{H}^{2}\right)$ as the ratio of the genetic to total component of variance, an appropriate measure for clones (Lynch and Walsh 1998). Data from the field-collected shoots were not included in our statistical analyses, but the mean and range of these shoots are presented on the figures to allow an assessment of whether the performance of any of the propagated genotypes was extreme relative to a larger sample of genotypes. Response variables were log transformed as necessary to meet assumptions of normality and homogeneity of variance. We present untransformed data in the figures. All analyses were conducted using JMP 5.0 (SAS Institute, Cary, NC). The specific methods and statistics for each of these categories are described in greater detail below.

\section{Morphology and production}

We quantified the total number of shoots and total rhizome length at the end of the common garden experiment as measures of production and spatial spread, respectively. We also measured maximum root length to examine the potential for variation in rooting depth. Finally, we quantified the biomass of shoot, root, and rhizome tissue that was dried at $60^{\circ} \mathrm{C}$ for at least $48 \mathrm{~h}$; these measurements were conducted separately for the original terminal shoots and any new tissue produced during the common garden experiment.

\section{Nutrient uptake}

Following the 10-week common garden period, we separated the original terminal shoot from any new shoots. We clipped a $1.5-\mathrm{cm}$ section of the $3 \mathrm{rd}$ rank leaf from the original terminal shoot for measures of photosynthetic rate (see below), and then used these original terminal shoots in nutrient uptake experiments. To examine the role of genotypic variation in nutrient uptake, we quantified biomassspecific leaf nitrate uptake and root/rhizome ammonium uptake using individual two-compartment chambers as in
Terrados and Williams (1997). Although all tissues are capable of utilizing multiple forms of nitrogen, we chose to test leaf nitrate and root/rhizome ammonium because these forms of nitrogen are most available in the water column and sediments, respectively. Roots/rhizomes were compartmentalized from leaf shoots by inserting the terminal shoot through a slit in a water-tight stopper separating a 500-ml transparent cylinder for the leaves from an opaque 40-ml chamber for the roots/rhizome. A submersible pump delivered turbulent water flow at $15.1 \mathrm{ml} \mathrm{s}^{-1}$ to the leaf chamber to prevent mass transfer limitation of uptake. The root compartment was unstirred and left aerobic because Zostera root and rhizomes release oxygen during active photosynthesis (Caffrey and Kemp 1990). The chambers were placed in a flow-through seawater table in a cold room at BML to maintain a constant ambient temperature (approximately $\left.15^{\circ} \mathrm{C}\right)$. Photosynthesis-saturating light $(860 \mu \mathrm{mol}$ photons $\mathrm{m}^{-2} \mathrm{~s}^{-1}$ ) was provided by four quartz halite lamps placed over the water table. Due to a limited number of nutrient chambers, we ran the experiments in batches of 14-15 clones at a time over a period of 3 weeks.

Nitrogen-free artificial seawater spiked to known initial concentrations (see below) was used in both the shoot and root/rhizome compartments. Prior to turning on the pumps and lights, we collected an initial 5-ml water sample from both the shoot and root compartments. We then collected a 5-ml sample from each leaf chamber every $45 \mathrm{~min}$ for $4 \mathrm{~h}$. A final 5-ml water sample was taken from the root chambers at the end of the experiment. Shoot compartment (nitrate) samples were frozen until analysis using a Lachat 8000 series flow injection auto analyzer. Root compartment (ammonium) samples were placed in acid-washed test tubes, kept in the dark, and analyzed spectrophotometrically (Koroleff 1976).

We conducted two separate uptake experiments (on consecutive days) for each clone to examine the effect of nutrient limitation on nitrate uptake. In one experiment, we spiked the artificial seawater in the root/rhizome compartments to $100 \mu \mathrm{M}$ using a $0.1 \mathrm{M}$ ammonium chloride solution (Orion), which approximates average sediment porewater ammonium concentrations in Bodega Harbor (A. R. Hughes, unpublished data). In the second experiment, no ammonium was added to the root chamber, resulting in initial ammonium concentrations of approximately $7 \mu \mathrm{M}$. In all experiments, we used a $0.1 \mathrm{M}$ sodium nitrate solution (Orion) to spike seawater for the shoot compartment to an initial nitrate concentration of approximately $15 \mu \mathrm{M}$, a representative concentration for the study area (Smith et al. 1989).

Change in nitrogen concentration was standardized by leaf biomass (nitrate) and root and rhizome biomass (ammonium); results did not differ when root biomass only was used for ammonium uptake (data not shown). We used nonlinear 
regression in order to estimate the biomass-specific first order rate constant $(k)$ for change in concentration over time. Given that biomass can vary among genotypes (see "Results"), we also calculated an estimate of total nutrient uptake for the experimental period [biomass-specific uptake rate $\left(\mathrm{mol} \mathrm{g}^{-1}\right.$ dry $) \times$ biomass $(\mathrm{g}$ dry $\left.)\right]$. To determine whether shoot nitrate uptake varied in response to the presence or absence of belowground ammonium, we conducted a factorial ANOVA with genotype and ammonium treatment (presence or absence) as fixed factors.

\section{Photosynthetic rate}

We generated photosynthesis (as oxygen evolution) versus irradiance ( $P$ vs. $I$ ) curves for each clone. As described above, after 10 weeks in the common garden environment we clipped a $1.5-\mathrm{cm}$ section $25 \mathrm{~cm}$ above the leaf sheath on the 3rd rank leaf of the original terminal shoot to be used in laboratory experiments of oxygen evolution. These shoot clippings were held in flow-through seawater for a minimum of $24 \mathrm{~h}$; this time period is sufficient to allow the tissue wounds from clipping to heal (S. L. Williams, unpublished data). We placed this tissue in a $2.3-\mathrm{ml}$ cuvette (Rank Brothers model) held at constant temperature $\left(12^{\circ} \mathrm{C}\right)$ and measured the change in oxygen concentration over a 3-min period at each of six irradiances: 75, 250, 500, 1,000, 1,500 , and 2,000 $\mu \mathrm{mol}$ photons $\mathrm{m}^{-2} \mathrm{~s}^{-1}$. The relationship between oxygen concentration and time was linear at each irradiance. We then dried and weighed the seagrass tissue after the experiment to standardize productivity by biomass. These data were fit to a nonlinear model using Talling's equation (Talling 1973) to estimate light-saturated photosynthesis $\left(P_{\max }\right)$ and the light-limited slope $(\alpha)$.

\section{Effects of intraclonal competition}

To assess the correspondence between physiological and growth measurements of single shoots and more natural situations in which multiple shoots are present initially, we compared variation among genotypes from this experiment with independent laboratory experiments using the same eight genotypes. The experimental design of these two additional experiments was similar to that described above, with the exception that two physically separated shoots (i.e., clones) of each genotype were planted initially rather than a single shoot (i.e., intraclonal competitors were present from the start of the experiment). In each of the two separate laboratory experiments, two clones of each genotype were planted in sieved sediment in individual $15-\mathrm{cm}-$ diameter pots and randomly assigned to locations in six mesocosms at BML. Shoot and rhizome lengths were standardized to 30 and $2.5 \mathrm{~cm}$, respectively, to minimize initial size differences. At the end of 12 weeks, we quantified total shoot production, aboveground biomass, belowground biomass, root to rhizome biomass ratio, rhizome length, and maximum root length.

We conducted a factorial ANOVA with genotype and experiment type (single vs. pair) as fixed factors to assess whether genotypic differences varied in the presence or absence of intraclonal competition. The presence of a significant genotype $\times$ experiment interaction would indicate that the effect of genotype is not consistent across the separate experiments.

Trade-offs in performance

We were interested a priori in two potential performance trade-offs among genotypes: allocation to vegetative versus reproductive shoot allocation, and aboveground nitrate uptake rate versus belowground ammonium uptake rate. In addition, we calculated the pair-wise correlations between the following response variables (grouped by genotype) to examine whether other trade-offs were evident in our data and whether these varied by genotype: vegetative shoot production, rhizome length, maximum root length, aboveground biomass, root biomass, rhizome biomass, the ratio of root to rhizome biomass, $P_{\max }, \alpha$, and biomass-specific ammonium and nitrate uptake rates.

Prediction of clonal identity

To examine whether genotypes can be predicted based solely on their similarity in ecological performance, we performed a linear discriminant analysis (DA) using the same response variables listed above as our predictors or input variables. We first input these observations along with the known genotypic identity; we then used the resultant discriminant functions to predict the genotypic identity of the same set of observations. The effectiveness of the DA is based on the percentage of observations that are assigned to the correct class (i.e., genotypic identity).

\section{Results}

Morphology and production

Zostera genotypes varied in biomass production and a variety of ecologically relevant morphological measures (Fig. 1). Broad-sense heritability values for these and other response ranged from 18.7 to $36.5 \%$. In addition to differences in shoot production (genotype $P<0.001, H^{2}=29.4$; Fig. 1a) and belowground biomass (genotype $P<0.001$, $H^{2}=25.9$; Fig. 1c) production, genotypes varied in the allocation of biomass to different tissues (e.g., the ratio of root to rhizome biomass, genotype $P=0.001, H^{2}=30.4$, 

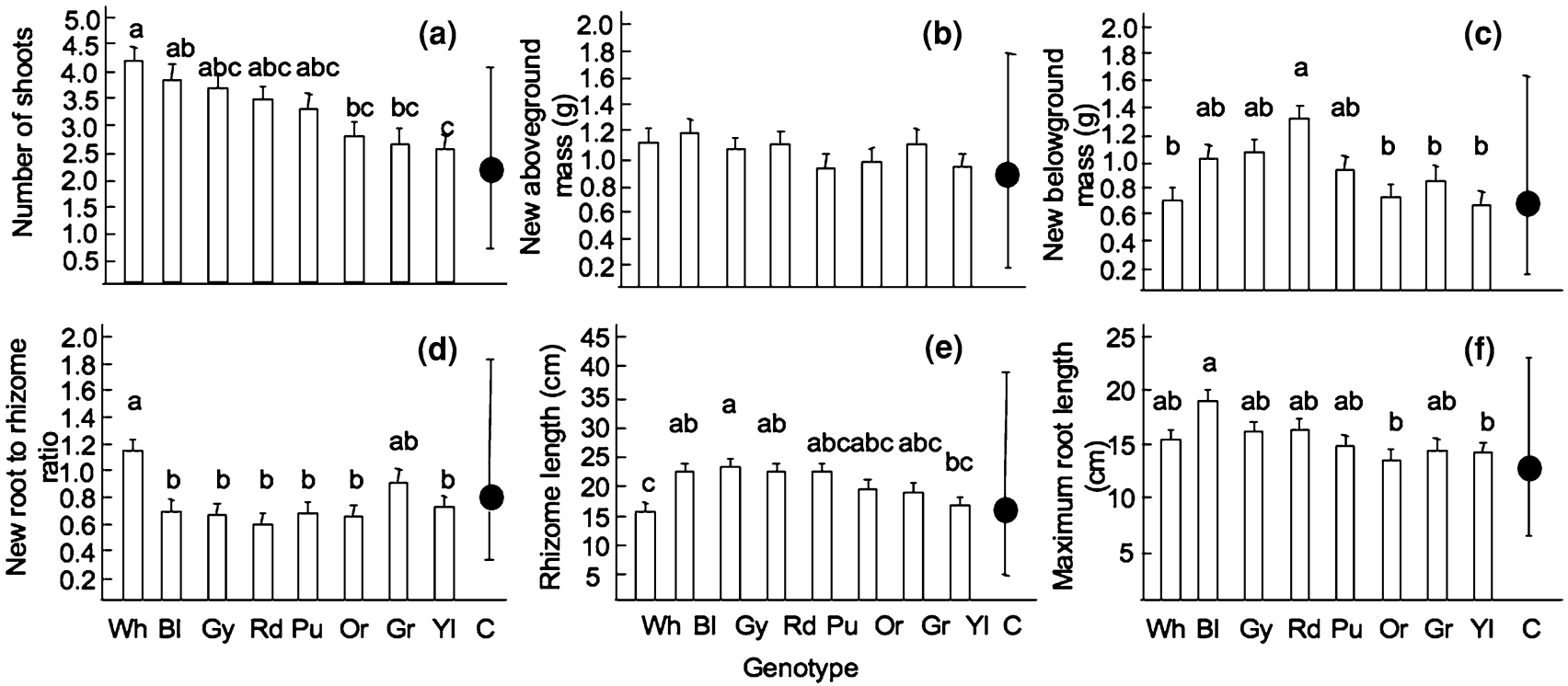

Fig. 1 Production and biomass variation among eight Zostera genotypes following a 10-week common garden experiment. a Shoot production. b Aboveground biomass produced during experiment. c Belowground biomass produced during experiment. d Ratio of root to rhizome biomass produced during experiment. e Rhizome length. f Maximum root length. Genotypes were coded by tag color [white

Fig. 1d; the ratio of above to belowground biomass, genotype $P<0.001, H^{2}=24.2$ ). Spatial spread (rhizome length; genotype $P=0.001, H^{2}=23.3$; Fig. 1e) and rooting depth (maximum root length; genotype $P=0.01, H^{2}=18.7$; Fig. 1f) also differed significantly. Interestingly, no one genotype maximized (or minimized) all response variables, or even those that would appear to be highly correlated (e.g., number of shoots and shoot mass; Fig. 1). Instead, the rank order of genotypes varied considerably from one response to the next (Pearson's $r ; P>0.05$ ). Only the rank order for belowground biomass, root to rhizome biomass, and rhizome length were significantly correlated (Pearson's $r P<0.01$ for each of these pairwise correlations).

\section{Nutrient uptake}

The eight Zostera genotypes examined here displayed significant variation in belowground biomass-specific ammonium uptake rate ( $k$; genotype $P=0.02, H^{2}=28.9$; Fig. 2 d). As with newly produced tissue, these genotypes also differed in total (newly produced plus tissue originally planted) belowground biomass (genotype $P<0.001$, $H^{2}=25.8$; Fig. 2e). As a result, estimated total ammonium uptake varied by genotype (genotype $P<0.001, H^{2}=32.4$; Fig. 2f), yet the rank order of estimated ammonium uptake (Fig. 2f) was different from the rank order of biomass-specific uptake (Fig. 2d).

Biomass-specific shoot uptake of nitrate also varied by genotype, both in the absence (genotype $P<0.001$,
$(W h)$, blue $(B l)$, gray $(G y)$, red $(R d)$, purple $(P u)$, orange $(O r)$, green $(G r)$, yellow $(Y l)]$. Control $(C)$ shoots were collected from the field at the start of the experiment. Means plus SE for genotypes $(n=7-10)$; means and range for field-collected shoots $(\mathrm{C}, n=15)$. Different letters indicate significant differences $(P<0.05)$ based on Tukey's post-hoc tests

$H^{2}=18.9$; Fig. 2a) and presence (genotype $P<0.001$, $H^{2}=23.3$ ) of belowground ammonium. Shoot nitrate uptake was higher overall when ammonium was absent from the roots/rhizomes (nutrient treatment $P<0.001$ ), and there was no genotype $\times$ ammonium treatment interaction $(P=0.99)$. Because total aboveground biomass did not vary across genotypes (genotype $P>0.05$; Fig. 2b), the rank order of estimated total nitrate uptake (Fig. 2c) was identical to the biomass-specific uptake rate (Fig. 2a).

Photosynthetic rate

Neither $P_{\max }$ nor $\alpha$ differed among Zostera genotypes (genotype $P>0.50$ ).

Effects of intraclonal competition

Genotypic effects on seagrass biomass and morphology were largely consistent in the presence and absence of clonemates (Table 1). However, two genotypes (blue and white) had significantly higher aboveground biomass in the presence of clonemates, leading to an interaction between genotype and experiment type. Maximum root length also exhibited a significant genotype $\times$ experiment interaction: most genotypes had longer roots on average in the presence of clonemates, although some (gray, purple and white) were not statistically longer and one genotype (blue) even showed the opposite pattern. 

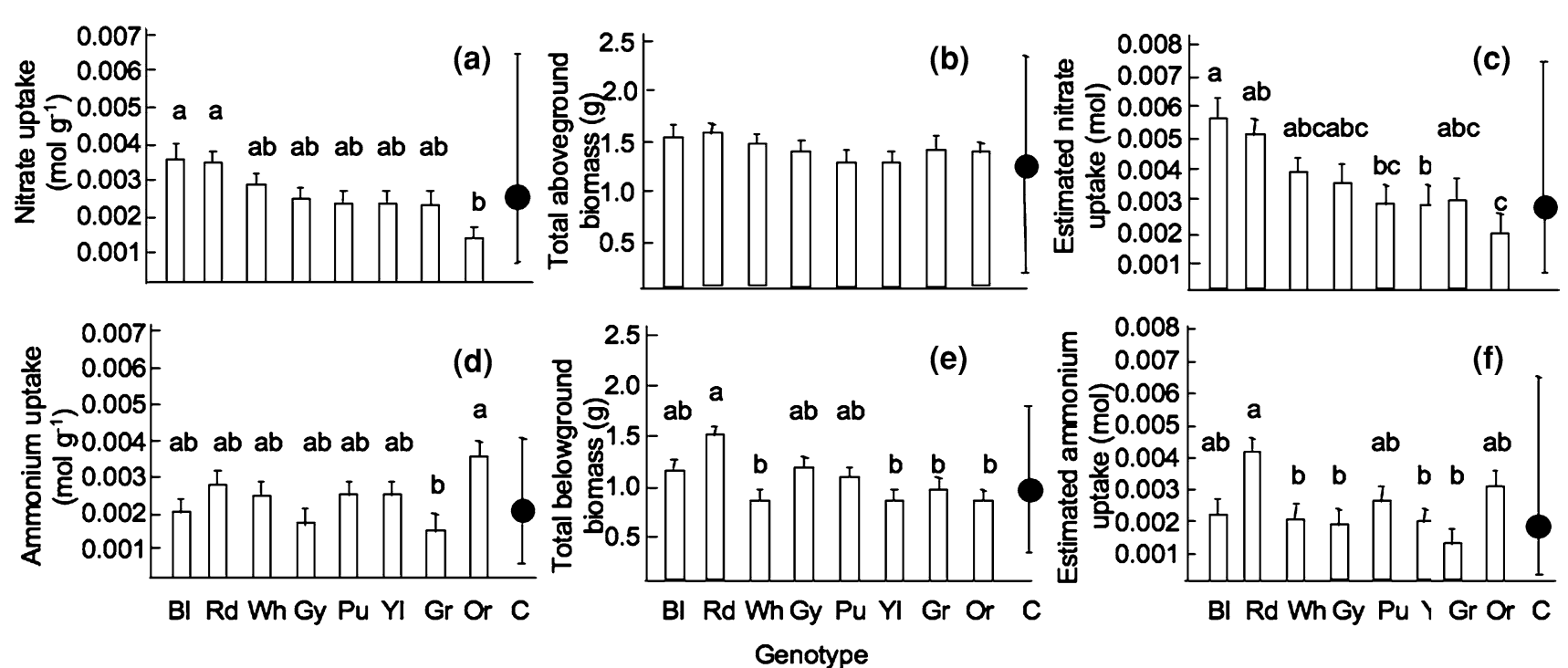

Fig. 2 Nutrient uptake variation among eight Zostera genotypes following a 10-week common garden experiment. a Biomass-specific shoot nitrate uptake. b Total aboveground biomass. $\mathbf{c}$ Estimated total nitrate uptake. d Biomass-specific root to rhizome ammonium uptake. e Total belowground biomass. e Estimated total ammonium uptake.
Genotypes were coded by tag color. C shoots were collected from the field at the start of the experiment. Means plus SE for genotypes $(n=7-10)$; means and range for field-collected shoots $(\mathrm{C}, n=15)$. Different letters indicate significant differences $(P<0.05)$ based on Tukey's post-hoc tests. For abbreviations, see Fig. 1

Table 1 Results of comparison of experiment type (with or without intraclonal competition)

\begin{tabular}{|c|c|c|c|c|c|c|c|}
\hline \multirow[t]{2}{*}{ Response } & \multirow[t]{2}{*}{$R^{2}$} & \multicolumn{2}{|c|}{ Genotype $(d f=7)$} & \multicolumn{2}{|c|}{ Experiment type $(d f=1)$} & \multicolumn{2}{|c|}{ Genotype $\times$ experiment $(d f=7)$} \\
\hline & & $F$ & $P$ & $F$ & $P$ & $F$ & $P$ \\
\hline Shoot production & 0.4 & 6.24 & $<0.0001$ & 26.49 & $<0.0001$ & 0.89 & 0.52 \\
\hline Aboveground biomass & 0.24 & 2.50 & 0.02 & 1.87 & 0.17 & 3.20 & 0.004 \\
\hline Belowground biomass & 0.34 & 6.56 & $<0.0001$ & 6.37 & 0.01 & 1.15 & 0.34 \\
\hline Root to rhizome ratio & 0.36 & 8.23 & $<0.0001$ & 1.87 & 0.17 & 0.87 & 0.53 \\
\hline Maximum root length & 0.45 & 1.86 & 0.08 & 51.42 & $<0.0001$ & 2.65 & 0.01 \\
\hline Rhizome length & 0.24 & 3.49 & 0.002 & 0.01 & 0.94 & 1.54 & 0.16 \\
\hline
\end{tabular}

Bold indicates significant effect

Trade-offs in performance

Although reproductive shoot production did not vary by genotype (genotype $P=0.13$ ), there was a significant trade-off between vegetative and reproductive shoot allocation overall $\left(R^{2}=0.41, P<0.0001\right)$. In contrast, there was no strong correlation between genotypic nitrate uptake and ammonium uptake $\left(R^{2}=0.13, P=0.38\right.$; Fig. 3$)$, although the genotype with the lowest biomass-specific nitrate uptake rate did have the highest biomass-specific ammonium uptake rate.

Few correlations among response variables for clones within genotype were significant, regardless of the particular genotype being considered (39 out of 288 possible correlations, or $13.5 \%$ ), most likely due to the low number of clones of each genotype. Rhizome length/belowground biomass and $P_{\max } / \alpha$ were consistently positively correlated across genotypes (75 and $62.5 \%$ of possible correlations,

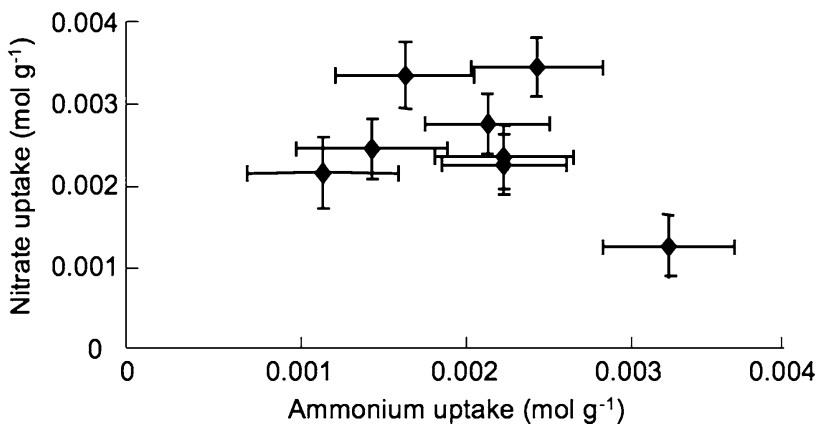

Fig. 3 Potential trade-offs in Zostera performance (means $\pm \mathrm{SE}$ ). Biomass-specific nitrate uptake versus biomass-specific ammonium uptake by genotype

respectively). Of the other significant correlations, a greater percentage was positive (71.4\%) than negative (28.6\%). In addition, the nature of the correlations varied by genotype, 



Fig. 4 Results of discriminant analysis. a Genotypic means along primary discriminant axes. Genotypes are distinguished by shapes: Wh (open circles), Gy (open square), Gr (open triangle), Rd (solid circle), Or (crosses), $\mathrm{B} 1$ (shaded diamond), Y1 (open diamond), $\mathrm{Pu}$ (star). b Predicted versus actual Zostera clonal identity. Genotypes are distinguished by shading of the bars: Wh (open), Gy (light gray), Gr (black), Re (right diagonal), Or (squares), B1 (horizontal stripe), Y1 (vertical stripe), $\mathrm{Pu}$ (dark gray). For abbreviations, see Fig. 1

with some exhibiting a higher percentage of significant correlations among response variables (range $=2.8-22.2 \%$ across genotypes).

\section{Prediction of clonal identity}

The DA classified $71 \%$ of the clones into the correct genotype (compared to a null hypothesis of $12.5 \%$ if clones were assigned randomly). However, the probability that a clone was misclassified varied by genotype (Fig. 4b): clones were reliably assigned to four of the genotypes with $80 \%$ or greater accuracy, while predictions for the remaining four genotypes were considerably less accurate, presumably because these genotypes displayed greater variability among clones in the measured performance traits (Fig. 4a).

\section{Discussion}

We found significant variation among Zostera genotypes for a wide variety of morphological and physiological responses; only aboveground biomass, flowering shoot production, and photosynthetic parameters did not vary consistently by genotype. In addition, there was no single genotype that maximized all performance measures simultaneously, providing evidence for functional differentiation among genotypes. These results imply that variation in niche space may contribute to genotypic coexistence in a manner analogous to differences in resource use among species (Tilman 1982). If so, it is possible that the ecological differences that we and others (Proffitt et al. 2003; Schweitzer et al. 2004; Johnson and Agrawal 2005) have identified among genotypes may contribute to the maintenance of genetic diversity in natural populations (e.g., high levels of seagrass genotypic diversity in some areas; Hughes and Stachowicz, in press). However, it is important to note that our results represent upper estimates of genetic variance, as they cannot rule out environmental carry-over or maternal effects.

We focused our analyses on eight Zostera genotypes that we propagated in the laboratory to ensure adequate replication of each genotype and provide a comparison for additional experiments. Despite that fact that these genotypes were initially selected haphazardly from the field with no a priori indication of morphological differences, they display significant variation that is relevant to community- and ecosystem-level processes. More importantly, the eight genotypes examined in this experiment appear to be representative of the variation present in natural settings, given that their average responses fell within the range exhibited by a broader array of field-collected genotypes (Figs. 1, 2). Given reductions in Zostera genetic variation (Williams 2001; Williams and Davis 1996), the conservation implications of these results and previous work in seagrass systems (e.g., Williams 2001; Hughes and Stachowicz 2004; Reusch et al. 2005) are clear: seagrass restoration efforts should include a diversity of genotypes (by increasing the spacing between transplants from a single bed, and/or by collecting transplants from multiple beds if inbreeding/outbreeding effects are known to be minimal; Ruckelshaus 1995) to enhance functional diversity and increase the likelihood of long-term persistence in the face of changing conditions.

In addition to significant variation among genotypes, we found that nitrate uptake rate was consistently higher when ammonium was abundant belowground than when ammonium was negligible. Leaf-root interactions governing nitrogen uptake in Zostera are complex (Iizumi and Hattori 1982; Short and McRoy 1984; Thursby and Harlin 1982) and a comprehensive kinetic understanding is lacking, but we are unaware of any other study that has shown a stimulation of nitrate uptake in the presence of belowground ammonium. Our goal in this study was to assess the potential for genotypic variation in nutrient uptake, but an 
interesting future direction will be to further examine the relative importance of and interactions between nitrate and ammonium uptake above- and belowground.

Our findings support conclusions from genetic diversity manipulations that multiple mechanisms likely contribute to the observed effects of genotypic diversity on ecosystem functioning (Hughes et al. 2004; Reusch et al. 2005; Johnson et al. 2006; reviewed in Hughes et al. 2008). For example, significant variation among genotypes in shoot production could lead to more diverse plots being more productive on average via a sampling effect (Huston 1997), given that a mixture is statistically more likely to contain a highly productive clone. In addition, if these more productive clones also have a competitive advantage, then they may increase in relative abundance (the selection effect; Tilman et al. 1997b) and further contribute to positive diversity effects. Of course the opposite can also occur: productive genotypes in monoculture can perform poorly in mixture, contributing to a negative selection effect (Reusch et al. 2005). Our results are also consistent with the finding that complementarity can contribute to positive effects of genotypic diversity (Reusch et al. 2005; Crutsinger et al. 2006) and indicate that niche partitioning is a likely mechanism, at least in seagrass systems. Zostera genotypes varied in their rate of uptake of both nitrate and ammonium, and different genotypes maximized these two responses; thus, total nitrogen uptake might be greater in more diverse beds. Furthermore, maximum rooting depth varied by genotype, suggesting that our laboratory uptake experiments (which effectively equalized rooting depth across clones) may have underestimated partitioning of belowground resource uptake.

Evolutionary biologists have long recognized the importance of genetically based variation within species-indeed every example of the operation of natural selection requires that genotypes differ in fitness-related traits. Despite this recognition by evolutionary biologists and the obvious implications for conservation and restoration, ecologists have been slow to appreciate the potential importance of genetic variation among individuals in ecological experiments. As we demonstrate here, it can explain a substantial portion of the observed variation $\left(R^{2} \leq 0.48\right)$ in many responses, including the ecosystem-level functions of primary production and nutrient acquisition. Furthermore, it is clear that habitat-forming plant species play an important role in organizing a wide range of ecosystems from forests, to marshes to kelp beds (Bruno et al. 2003; Ellison et al. 2005; Halpern et al. 2007). We now have several studies that demonstrate that key traits of these foundation species vary among plant genotypes (reviewed by Whitham et al. 2006). Thus, genetic variation in foundation species may often have measurable effects on community composition, structure, and function and should not be ignored.
Acknowledgements We thank A. Fish and A. Carranza for laboratory assistance. This work was supported by NSF grant OCE-06-23641 to J. J. S. and A. R. H. and NSF grant OCE-0196078 to S. L. W. These experiments comply with the current laws of the USA.

Open Access This article is distributed under the terms of the Creative Commons Attribution Noncommercial License which permits any noncommercial use, distribution, and reproduction in any medium, provided the original author(s) and source are credited.

\section{References}

Bolnick DI, Svanback R, Fordyce JA, Yang LH, Davis JM, Hulsey CD, Forister ML (2003) The ecology of individuals: incidence and implications of individual specialization. Am Nat 161:1-28

Bruno JF, Stachowicz JJ, Bertness MD (2003) Inclusion of facilitation into ecological theory. Trends Ecol Evol 18:119-125

Caffrey JM, Kemp WM (1990) Nitrogen cycling in sediments with estuarine populations of $P$. perfoliatus and Z. marina. Mar Ecol Prog Ser 66:147-160

Cardinale BJ, Wright JP, Cadotte MW, Carroll IT, Hector A, Srivastava DS, Loreau M, Weis JJ (2007) Impacts of plant diversity on biomass production increase through time because of species complementarity. Proc Natl Acad Sci USA 104:18123-18128

Clark JS, LaDeau S, Ibanez I (2004) Fecundity of trees and the colonization-competition hypothesis. Ecol Monogr 74:415-442

Crutsinger GM, Collins MD, Fordyce JA, Gompert Z, Nice CC, Sanders NJ (2006) Plant genotypic diversity predicts community structure and governs an ecosystem process. Science 313:966-968

Dayton PK (1972) Toward an understanding of community resilience and the potential effects of enrichments to the benthos at McMurdo Sound, Antarctica. In: Parker BC (ed) Proceedings of the colloquium on conservation problems in Antarctica. Allen Press, Lawrence

Dennison WC, Alberte RS (1982) Photosynthetic responses of Zostera marina to in situ manipulations of light intensity. Oecologia 55:137-144

Dennison WC, Alberte RS (1985) Role of daily light period in the depth distribution of Zostera marina (eelgrass). Mar Ecol Prog Ser 25:51-61

Dennison WC, Alberte RS (1986) Photoadaptation and growth of Zostera marina L. (eelgrass) transplants along a depth gradient. J Exp Mar Biol Ecol 98:265-282

Dennison WC, Aller RC, Alberte RS (1987) Sediment ammonium availability and eelgrass (Zostera marina) growth. Mar Biol 94:469-477

Ellison AM, Bank MS, Clinton BD, Colburn EA, Elliott K, Ford CR, Foster DR, Kloeppel BD, Knoepp JD, Lovett GM, Mohan J, Orwig DA, Rodenhouse NL, Sobczak WV, Stinson KA, Stone JK, Swan CM, Thompson J, Von Holle B, Webster JR (2005) Loss of foundation species: consequences for the structure and dynamics of forested ecosystems. Front Ecol Environ 3:479-486

Halpern BS, Silliman BR, Olden JD, Bruno JF, Bertness MD (2007) Incorporating positive interactions in aquatic restoration and conservation. Front Ecol Environ 5:153-160

Hughes AR, Stachowicz JJ (2004) Genetic diversity enhances the resistance of a seagrass ecosystem to disturbance. Proc Natl Acad Sci USA 101:8998-9002

Hughes AR, Stachowicz JJ (in press) Ecological impacts of genotypic diversity in the clonal seagrass Zostera marina. Ecology

Hughes AR, Bando KJ, Rodriguez LF, Williams SL (2004) Relative effects of grazers and nutrients on seagrasses: a meta-analysis approach. Mar Ecol Progr Ser 282:87-99 
Hughes AR, Inouye BD, Johnson MTJ, Vellend M, Underwood N (2008) Ecological consequences of genetic diversity. Ecol Lett 11:609-623

Huston MA (1997) Hidden treatments in ecological experiments: re-evaluating the ecosystem function of biodiversity. Oecologia 110:449-460

Iizumi H, Hattori A (1982) Growth and organic production of eelgrass (Zostera marina L.) in temperate waters of the Pacific coast of Japan. III. The kinetics of nitrogen uptake. Aquat Bot 12:245-256

Johnson MTJ, Agrawal AA (2005) Plant genotype and environment interact to shape a diverse arthropod community on Evening Primrose (Oenothera biennis). Ecology 86:874-885

Johnson MTJ, Lajeunesse MJ, Agrawal AA (2006) Additive and interactive effects of plant genotypic diversity on arthropod communities and plant fitness. Ecol Lett 9:24-34

Koroleff F (1976) Determination of ammonia. In: Grasshoff K (ed) Methods of seawater analysis. Verlag Chemie, Weinheim

Lankau RA, Strauss SY (2007) Mutual feedbacks maintain both genetic and species diversity in a plant community. Science 317:1561-1563

Lynch M, Walsh B (1998) Genetics and analysis of quantitative traits. Sinauer, Sunderland

McMillan C (1978) Morphogeographic variation under controlled conditions in five seagrasses, Thalassia testudinum, Halodule wrightii, Syringodium filiforme, Halophila engelmanii and Zostera marina. Aquat Bot 4:169-189

Moore KA, Short FT (2006) Zostera: biology, ecology, and management. In: Larkum AWD, Orth RJ, Duarte CM (eds) Seagrasses: biology, ecology, and conservation. Springer, The Netherlands

Norberg J, Swaney DP, Dushoff J, Lin J, Casagrandi R, Levin SA (2001) Phenotypic diversity and ecosystem functioning in changing environments: a theoretical framework. Proc Natl Acad Sci USA 98:11376-11381

Orth RJ, Carruthers TJB, Dennison WC, Duarte CM, Fourqurean JW, Heck KL Jr, Hughes AR, Kendrick GA, Kenworthy WJ, Olyarnik S, Short FT, Waycott M, Williams SL (2006) A global crisis for seagrass ecosystems. Bioscience 56:987-996

Proffitt CE, Travis SE, Edwards KR (2003) Genotype and elevation influence Spartina alterniflora colonization and growth in a created salt marsh. Ecol Appl 13:180-192

Reusch TBH, Bostroem C, Stam WT, Olsen JL (1999a) An ancient eelgrass clone in the Baltic. Mar Ecol Prog Ser 183:301-304

Reusch TBH, Stam WT, Olsen JL (1999b) Microsatellite loci in eelgrass Zostera marina reveal marked polymorphism within and among populations. Mol Ecol 8:317-322

Reusch TBH, Stam WT, Olsen JL (2000) A microsatellite-based estimation of clonal diversity and population subdivision in Zostera marina, a marine flowering plant. Mol Ecol 9:127-140

Reusch TBH, Ehlers A, Haemmerli A, Worm B (2005) Ecosystem recovery after climatic extremes enhanced by genotypic diversity. Proc Natl Acad Sci USA 102:2826-2831

Romero J, Lee K, Perez M, Mateo MA, Alcoverro T (2006) Nutrient dynamics in seagrass ecosystems. In: Larkum AWD, Orth RJ,
Duarte CM (eds) Seagrasses: biology, ecology, and conservation. Springer, Dordrecht

Ruckelshaus MH (1995) Estimates of outcrossing rates and of inbreeding depression in a population of the marine angiosperm Zostera marina. Mar Biol 123:583-593

Schweitzer JA, Bailey JK, Rehill BJ, Martinsen GD, Hart SC, Lindroth RL, Keim P, Whitham TG (2004) Genetically based trait in a dominant tree affects ecosystem processes. Ecol Lett 7:127-134

Short FT, McRoy CP (1984) Nitrogen uptake by leaves and roots of the seagrass Zostera marina L. Bot Mar 27:547-555

Smith SV, Hollibaugh JT, Dollar SJ, Vink S (1989) Tomales Bay, California: a case for carbon-controlled nitrogen cycling. Limnol Oceanogr 34:37-52

Talling JF (1973) The application of some electrochemical methods to the measurement of photosynthesis and respiration in fresh waters. Freshwater Biol 3:335-362

Taylor RB, Lindquist N, Kubanek J, Hay ME (2003) Intraspecific variation in palatability and defensive chemistry of brown seaweeds: effects on herbivore fitness. Oecologia 136:412-423

Terrados J, Williams SL (1997) Leaf versus root nitrogen uptake by the surfgrass Phyllospadix torrey. Mar Ecol Prog Ser 149:267-277

Thayer GW, Kenworthy WJ, Fonseca MS (1984) The ecology of eelgrass meadows of the Atlantic coast: a community profile. US Fish and Wildlife Service. FWS/OBS-84/O2

Thursby GB, Harlin MM (1982) Leaf-root interaction in the uptake of ammonia by Zostera marina. Mar Biol 72:109-112

Tilman D (1982) Resource competition and community structure. Princeton University Press, Princeton

Tilman D (1999) The ecological consequences of changes in biodiversity: a search for general principles. Ecology 80:1455-1474

Tilman D, Knops J, Wedin D, Reich P, Ritchie M, Siemann E (1997a) The influence of functional diversity and composition on ecosystem processes. Science 277:1300-1302

Tilman D, Lehman CL, Thomson KT (1997b) Plant diversity and ecosystem productivity: theoretical considerations. Proc Natl Acad Sci USA 94:1857-1861

Whitham TG, Bailey JK, Schweitzer JA, Shuster SM, Bangert RK, LeRoy CJ, Lonsdorf EV, Allan GJ, DeFazio SP, Potts BM, Fischer DG, Gehring CA, Lindroth RL, Marks JC, Hart SC, Wimp GM, Wooley SC (2006) A framework for community and ecosystem genetics: from genes to ecosystems. Nat Rev Genet $7: 510-523$

Williams SL (2001) Reduced genetic diversity in eelgrass transplantations affects both population growth and individual fitness. Ecol Appl 11:1472-1488

Williams SL, Davis CA (1996) Population genetic analyses of transplanted eelgrass (Zostera marina) beds reveal reduced genetic diversity in southern California. Restor Ecol 4:163-180

Wright S (1920) The relative importance of heredity and environment in determining piebald pattern of guinea-pigs. Proc Natl Acad Sci USA $6: 320-332$ 